\title{
Sildenafil Reverses Hypoxic Pulmonary Hypertension in Highland and Lowland Newborn Sheep
}

\author{
EMILIO A. HERRERA, GERMÁN EBENSPERGER, BERNARDO J. KRAUSE, RAQUEL A. RIQUELME, ROBERTO V. REYES, \\ MARÍA CAPETILLO, SERGIO GONZÁLEZ, JULIAN T. PARER, AND ANÍBAL J. LLANOS
}

\begin{abstract}
Program in Pathophysiology [E.A.H., G.E., B.J.K., R.V.R., A.J.L.], Department of Pathology, [M.C.], University of Chile, CP 6640871 Santiago, Chile; Department of Biochemistry and Molecular Biology [R.A.R.], University of Chile, CP 8380492 Santiago, Chile; International Center for Andean Studies (INCAS) [E.A.H., A.J.L.], CP 8330015, Santiago, Chile; Department of Pathological Anatomy [S.G.], Pontificia Catholic University of Chile, CP 8330074 Santiago, Chile; University of Tarapacá [G.E., A.J.L.], CP 1000007, Arica, Chile; Department of Obstetrics, Gynecology and Reproductive Sciences [J.T.P.], University of California-San Francisco, San Francisco,
\end{abstract} California 94143

\begin{abstract}
Perinatal exposure to chronic hypoxia induces sustained hypertension and structural and functional changes in the pulmonary vascular bed. We hypothesized that highland newborn lambs (HLNB, $3600 \mathrm{~m}$ ) have a higher pulmonary arterial pressure (PAP) due in part to a higher activity/expression of phosphodiesterase 5 (PDE5). We administered sildenafil, a PDE5 inhibitor, during basal and hypoxic conditions in the pulmonary hypertensive HLNB and compared them to lowland newborn lambs (LLNB, $580 \mathrm{~m}$ ). Additionally, we compared the vasodilator responses to sildenafil in isolated small pulmonary arteries and the PDE5 mRNA expression and evaluated the vascular remodeling by histomorphometric analysis in these newborn lambs. Under basal conditions, HLNB had a higher PAP and cardiac output compared with LLNB. Sildenafil decreased the PAP during basal conditions and completely prevented the PAP increase during hypoxia in both groups. HLNB showed a greater contractile capacity and a higher maximal dilation to sildenafil. PDE5 mRNA expression did not show significant differences between HLNB and LLNB. The distal pulmonary arteries showed an increased wall thickness in HLNB. Our results showed that HLNB are more sensitive to sildenafil and therefore could be useful for treatment of pulmonary hypertension in high-altitude neonates.

(Pediatr Res 63: 169-175, 2008)
\end{abstract}

$\mathrm{E}^{\mathrm{x}}$ posure of lowland species to high altitude produces pulmonary vasoconstriction and remodeling resulting in pulmonary hypertension. Previously, we have shown that newborn lambs gestated and born at high altitude have an increased pulmonary arterial pressure (PAP) and vascular reactivity compared with those born at sea level (1). Appropriate increases in pulmonary vascular resistance (PVR) are adaptive, matching pulmonary perfusion to the reduced oxygenation. However, excessive increases in PVR, if maintained over time, lead to structural changes of the pulmonary vasculature, such as an increase in vascular muscle cells and fibrosis

Received June 11, 2007; accepted September 12, 2007.

Correspondence: Aníbal J. Llanos, M.D., Programa de Fisiopatología, Instituto de Ciencias Biomédicas, Universidad de Chile, Postal Code 6640871, Providencia, Santiago, Chile; e-mail: allanos@med.uchile.cl

Provided by grants FONDECYT 1010636-1050479, The Wellcome Trust CRIG 072256 and ALFA Program Project No. II-0379-FCD.

B.J.K. current address: Department of Basic Sciences, University of Bío-Bío, Concepcion, Chile. in the adventitia of the vessel (2-4). In newborns, either at altitude or sea level, this pulmonary arterial hypertension is ultimately due to a failure in the regulation of the PVR at birth by mechanisms not fully understood, which implies an imbalance in vasoconstrictors and vasodilators, leading to hypoxemia and sustained pulmonary hypertension. Indeed, one of the major causes of persistent pulmonary hypertension in the newborn is chronic hypoxia in utero (5) and is characterized by hypoxemia that is frequently refractory to conventional management, with a mortality rate near $10 \%$ (6). The incidence of this syndrome may be higher at high altitudes (7), an important issue considering that more than 140 million people worldwide live at more than $2500 \mathrm{~m}$ (8). Moreover, it has been suggested that during chronic hypoxia, production of vasoconstrictors is enhanced, while synthesis of vasodilators is reduced in the lung $(9,10)$. A mechanism that favors this high vascular tone is the hydrolysis of cyclic guanosine monophosphate (cGMP) by phosphodiesterases (PDEs). The major PDEs expressed in arterial smooth muscle cells of mammals, including pulmonary arteries, are the PDEs $1 \mathrm{~A}, 1 \mathrm{~B}, 1 \mathrm{C}, 3 \mathrm{~A}$, $3 \mathrm{~B}$, and 5. In conditions of low intracellular calcium, PDE5 presents the most important cGMP-hydrolyzing activity (11). PDE5 activity is increased by high levels of cGMP, which binds to a specific regulatory domain (GAF) and induces its phosphorylation through protein kinase G (PKG I). This fact explains in part the tolerance that is developed in response to the antihypertensive treatments with nitric oxide (NO)releasing drugs (11). Therefore, the inhibition of PDE5 activity seems to be a suitable strategy to confront the high vascular tone observed in pulmonary hypertension.

Current treatment for pulmonary hypertension includes inhaled NO with partially successful results; however, NO presents the disadvantage of being an expensive treatment.

\footnotetext{
Abbreviations: cGMP, cyclic guanosine monophosphate; $\mathbf{C O}$, cardiac output; HLNB, highland gestated and born neonatal lamb; HR, heart rate; LLNB, lowland gestated and born neonatal lamb; PAP, pulmonary arterial pressure; PDE5, phosphodiesterase 5; PVR, pulmonary vascular resistance; SAP, systemic arterial pressure; sGC, soluble guanylate cyclase; SNP, sodium nitroprusside; SVR, systemic vascular resistance
} 
Furthermore, the availability of this gas around the world is limited. Sildenafil is a competitive inhibitor of the PDE5 that has been suggested as a treatment for pulmonary hypertension in newborns $(12,13)$. Here, we studied the use of sildenafil as an antihypertensive drug in the pulmonary vasculature of lambs exposed to chronic hypoxia during the perinatal period and explored the role of PDE5 and cGMP on the NO-induced vasodilatation in isolated pulmonary arteries. We hypothesized that neonatal sheep native to highlands have a higher PAP due in part to a higher expression/activity of PDE5 relative to lowland lambs. The aim of this study was to determine the pulmonary and systemic cardiorespiratory effects of i.v. administration of sildenafil during basal and hypoxic conditions in newborn lambs whose pregnancy and birth took place at $3600 \mathrm{~m}$ above sea level and compared them with those born at sea level. Additionally, we compared the vasodilator responses in isolated small pulmonary arteries to sildenafil and sodium nitroprusside (SNP, a NO donor) and evaluated the vascular remodeling by histomorphometric analysis.

\section{METHODS}

The Ethical Committee of the Faculty of Medicine, University Of Chile, approved all animal procedures.

Animal subjects. We used 21 newborn sheep gestated, born, and studied at Santiago, $580 \mathrm{~m}$ (lowland newborn (LLNB), weight of $7.0 \pm 0.4 \mathrm{~kg}$ ) and 13 newborn sheep gestated, born, and studied at the Putre Research Station at $3600 \mathrm{~m}$ (highland newborn (HLNB), weight of $5.6 \pm 0.4 \mathrm{~kg}$ ) for the in vivo studies (8-12 d old) (1). An additional five LLNB and six HLNB were euthanized (thiopentone overdose) and their lungs dissected for ex vivo reverse transcriptase polymerase chain reaction (RT-PCR) and histologic analysis.

Surgical preparation. The lambs (3-5 d old) received atropine $(0.04 \mathrm{mg}$ $\mathrm{kg}^{-1}$ i.m. Atropina Sulfato, Laboratorio Chile) and ketamine-diazepam combination $\left[10 \mathrm{mg} \cdot \mathrm{kg}^{-1}\right.$ i.m. (Ketostop, Drag Pharma-Invectec), and 0.1-0.5 $\mathrm{mg} \cdot \mathrm{kg}^{-1}$ i.m. Diazepam (Laboratorio Biosano)] as general anesthesia. Polyvinyl (1.2 $\mathrm{mm}$ internal diameter) and a Swan-Ganz catheters (Edwards Swan-Ganz 5 French, Baxter Healthcare Corporation) were placed in the descending aorta, inferior vena cava, and pulmonary artery. All catheters were exteriorized and kept in a pouch sewn onto the skin. Ampicillin $10 \mathrm{mg} \cdot \mathrm{kg}^{-1}$ i.v. (Ampicilina, Laboratorio Best-Pharma), were given every $12 \mathrm{~h}$ while the animals were instrumented. The experiments commenced at least $3 \mathrm{~d}$ after surgery.

In vivo experiments. All experiments had $45 \mathrm{~min}$ of basal (B), $15 \mathrm{~min}$ of basal plus infusion $(\mathrm{B}+\mathrm{I}), 60 \mathrm{~min}$ of isocapnic hypoxia plus infusion $(\mathrm{H}+\mathrm{I}$, $\mathrm{Po}_{2} 30 \mathrm{~mm} \mathrm{Hg}$ ) and $60 \mathrm{~min}$ of recovery $(\mathrm{R})$. To induce hypoxia, a transparent polyethylene bag was placed over the animal's head into which a mixture of air, $\mathrm{N}_{2}$, and $\mathrm{CO}_{2}\left(10 \% \mathrm{O}_{2}\right.$ and $2 \%-3 \% \mathrm{CO}_{2}$ in $\left.\mathrm{N}_{2}\right)$ was passed at $20 \mathrm{~L} \cdot \mathrm{min}^{-1}$. Fourteen LLNB and seven HLNB received an i.v. infusion of $0.9 \% \mathrm{NaCl}$ as the control group. Seven LLNB and six HLNB were treated with sildenafil (Sildenafil, Laboratorio Chile; $16.6 \mu \mathrm{g} \cdot \mathrm{kg}^{-1} \cdot \mathrm{min}^{-1}$ i.v.). The solutions were infused 15 min before hypoxia and ran continuously until the end of the hypoxic challenge $(\mathrm{B}+\mathrm{I}$ and $\mathrm{H}+\mathrm{I})$.

Arterial $\mathrm{pH}, \mathrm{PO}_{2}, \mathrm{PCO}_{2}$, hemoglobin concentration $(\mathrm{Hb})$, percentage of saturation of hemoglobin $\left(\mathrm{SaO}_{2}\right)$, and oxygen content; systemic arterial pressure (SAP) and PAP; heart rate (HR) and mean SAP and PAP; cardiac output (CO); and systemic vascular resistance (SVR) and PVR were measured and calculated as described previously (1).

Ex vivo experiments. Small resistance pulmonary arteries (third branch, $370 \pm 18 \mu \mathrm{m}$ internal diameter, $2 \mathrm{~mm}$ length) were dissected and mounted in a myograph (410M, Dual Wire Myograph, Danish Myotechnology) for isometric force measurement. We obtained the optimal diameter and concentration response curves to potassium and dose-dependent relaxation in precontracted arteries with $\mathrm{K}-\mathrm{KBR}(50 \mathrm{mM} \mathrm{KCl})$ to SNP $\left(10^{-11}\right.$ to $\left.10^{-3} \mathrm{M}\right)$, to sildenafil $\left(10^{-13}-10^{-5} \mathrm{M}\right)$ and to SNP in the presence of $10^{-5} \mathrm{M}$ ODQ (1H-[1,2,4]oxadiazolo[4,3-a]quinoxalin-1-one), a specific inhibitor of the soluble guanylate cyclase (sGC).

PDE5 mRNA determination. We prepared total RNA using Trizol (Invitrogen Life Technologies, Carlsbad, CA) and synthesized cDNA by RT using random hexamers and the SuperScript First Strand Synthesis System for RT-PCR kit (Invitrogen Life Technologies). PCR amplification of partial sequences of DNA coding for PDE5 was carried out from cDNA synthesized from $0.2 \mu \mathrm{g}$ of total RNA, with $1 \mathrm{U}$ of Taq polymerase (Promega); $1.5 \mathrm{mM}$ $\mathrm{MgCl}_{2} ; 0.2 \mathrm{mM}$ deoxyribonucleoside triphosphate mix; and $0.3 \mu \mathrm{m}$ of each one of the primers used. Primers used were forward $5^{\prime}$-CARAAYTTYCARATGAAMCAYGA- $3^{\prime}$ and reverse $5^{\prime}$-RTTYTTYTTYTCYCKRTTCAT- $3^{\prime}$ for specific amplification of $700 \mathrm{bp}$. The PCR reaction profile consisted of $5 \mathrm{~min}$ at $94^{\circ} \mathrm{C}$, followed by 28 cycles of $40 \mathrm{~s}$ at $94^{\circ} \mathrm{C}, 1 \mathrm{~min}$ at $53.5^{\circ} \mathrm{C}, 1$ min at $72^{\circ} \mathrm{C}$, and extension for $5 \mathrm{~min}$ at $72^{\circ} \mathrm{C}$. Fifteen microliters of each PCR products was separated by electrophoresis on ethidium bromide agarose gels and visualized under ultraviolet light. The bands obtained on RT-PCR determinations were quantified by densitometric analysis using the Scion Image Software (Scion Image Beta 4.02, Scion Corporation, Frederick, MD).

Histologic experiments. We extracted and perfused the left lung with $4 \%$ paraformaldehyde. Excised lungs were fixed in $4 \%$ paraformaldehyde for $24 \mathrm{~h}$ at $4^{\circ} \mathrm{C}$ and embedded in paraffin, and van Gieson staining was performed on $10-\mu \mathrm{m}$ slides. For pulmonary vascular morphometry, images of subpleural arterioles were captured with a microscope digital camera system (Nikon Coolpix), and arterial area was measured using an image analysis program (ImageJ 1.32J National Institutes of Health, Bethesda, $\mathrm{MD})$. The percentage of wall thickness was calculated as described by Minamino et al. (14).

The solutions and drugs used were as follows. Krebs buffer was prepared as described previously (1). Sildenafil was obtained from Laboratorio Chile, SNP from Prolabo (Paris, France), and ODQ from Sigma Chemical Co.

Data analysis. We used two-way ANOVA and the Newman-Keuls test for in vivo studies. For ex vivo experiments, dose-response curves were analyzed in terms of sensitivity and maximal response by fitting experimental data to the Boltzmann equation (Origin v. 5.0, MicroCal, Northampton, MA). Contractile responses were expressed in terms of tension $(\mathrm{N} / \mathrm{m})$ and relaxation responses as a percentage of reduction of $125 \mathrm{mM} \mathrm{K}^{+}$-induced contraction or tension $(\mathrm{N} / \mathrm{m})$. Sensitivity was calculated as $\mathrm{pD}_{2}$, where $\mathrm{pD}_{2}=$ $-\log \left[\mathrm{EC}_{50}\right], \mathrm{EC}_{50}$ being the concentration at which $50 \%$ of the maximal response was obtained. For myographic, RT-PCR, and histologic experiments, differences were assessed by a $t$ test. Data are shown as means \pm SEM and were considered significant if $p<0.05$.

\section{RESULTS}

Blood gases and acid-base status. During the basal period, $\mathrm{PaO}_{2}, \mathrm{PaCO}_{2}, \mathrm{SaO}_{2}$, and $\mathrm{O}_{2}$ content were lower in HLNB than in LLNB, but $\mathrm{pH}$ was higher (Table 1). During acute hypoxia, all animals had decreases in $\mathrm{PaO}_{2}, \mathrm{SaO}_{2}$, and $\mathrm{O}_{2}$ content, but the $\mathrm{PaO}_{2}$ was maintained (isocapnic hypoxia) (Table 1). During recovery, the altered variables returned to basal values in both groups, with few exceptions (Table 1). The control and sildenafil-treated groups at the same altitude presented similar blood gases during the experimental periods (Table 1).

HLNB. The HLNB had an increased PAP and PVR compared with LLNB (Figs. 1 and 2). Furthermore, they showed an increase in PAP and HR during the hypoxic onset, with an increase in PVR (Figs. 1 and 2, Table 2). In contrast, neither SAP nor SVR showed changes during this episode (Table 2). All the cardiovascular variables returned to basal values in the recovery period in the control group (Figs. 1 and 2, Table 2). With the sildenafil infusion, there was an initial decrease in PAP and SAP with an increase in HR (Fig. 1, Table 2). During the hypoxic episode with sildenafil, PAP and PVR were maintained at lower levels (Figs. 1 and 2). In contrast, the SAP recovered to the initial basal values during the first $15 \mathrm{~min}$ of hypoxia; nevertheless, SVR remained low. In addition, HR and $\mathrm{CO}$ increased as in the control group during hypoxia (Table 2). At the end of the recovery period, all variables returned to basal values, except for PAP and PVR, which remained lower than the control group. 
Table 1. Arterial pH and blood gases in HLNB and LLNB during the experimental protocol of NaCl $0.9 \%$ (control) or sildenafil infusion

\begin{tabular}{|c|c|c|c|c|}
\hline & Basal & Basal + I & Hypoxia + I & Recovery \\
\hline \multicolumn{5}{|l|}{$\mathrm{pHa}$} \\
\hline \multicolumn{5}{|l|}{ HLNB } \\
\hline $\mathrm{NaCl} 0.9 \%$ & $7.456 \pm 0.007 *$ & $7.448 \pm 0.008 *$ & $7.433 \pm 0.012$ & $7.414 \pm 0.015 \dagger$ \\
\hline Sildenafil & $7.463 \pm 0.007$ & $7.414 \pm 0.041 \dagger$ & $7.409 \pm 0.028 \dagger$ & $7.435 \pm 0.016$ \\
\hline \multicolumn{5}{|l|}{ LLNB } \\
\hline $\mathrm{NaCl} 0.9 \%$ & $7.412 \pm 0.014$ & $7.407 \pm 0.013$ & $7.391 \pm 0.019$ & $7.423 \pm 0.018$ \\
\hline Sildenafil & $7.460 \pm 0.016$ & $7.445 \pm 0.012$ & $7.424 \pm 0.018$ & $7.455 \pm 0.013$ \\
\hline \multicolumn{5}{|l|}{$\mathrm{PaO}_{2}(\mathrm{~mm} \mathrm{Hg})$} \\
\hline \multicolumn{5}{|l|}{ HLNB } \\
\hline $\mathrm{NaCl} 0.9 \%$ & $41.6 \pm 2.8^{*}$ & $39.3 \pm 2.6^{*}$ & $31.3 \pm 0.5 \dagger$ & $42.9 \pm 3.9^{*}$ \\
\hline Sildenafil & $43.4 \pm 0.6$ & $41.8 \pm 1.4$ & $28.8 \pm 1.0 \dagger$ & $43.3 \pm 1.7$ \\
\hline \multicolumn{5}{|l|}{ LLNB } \\
\hline $\mathrm{NaCl} 0.9 \%$ & $79.5 \pm 1.9$ & $77.7 \pm 3.4$ & $30.9 \pm 0.6 \dagger$ & $82.4 \pm 3.8$ \\
\hline Sildenafil & $83.7 \pm 3.3$ & $78.2 \pm 2.3$ & $30.5 \pm 0.4 \dagger$ & $82.8 \pm 1.6$ \\
\hline \multicolumn{5}{|l|}{$\mathrm{PaCO}_{2}(\mathrm{~mm} \mathrm{Hg})$} \\
\hline \multicolumn{5}{|l|}{ HLNB } \\
\hline $\mathrm{NaCl} 0.9 \%$ & $31.6 \pm 1.8^{*}$ & $31.8 \pm 1.8^{*}$ & $31.8 \pm 1.6^{*}$ & $31.1 \pm 1.8^{*}$ \\
\hline Sildenafil & $34.4 \pm 1.1$ & $36.8 \pm 2.9$ & $35.2 \pm 1.7$ & $33.6 \pm 1.2$ \\
\hline \multicolumn{5}{|l|}{ LLNB } \\
\hline $\mathrm{NaCl} 0.9 \%$ & $36.8 \pm 1.1$ & $36.9 \pm 1.3$ & $35.8 \pm 1.2$ & $32.4 \pm 1.4 \dagger$ \\
\hline Sildenafil & $38.2 \pm 1.5$ & $38.0 \pm 1.4$ & $39.0 \pm 1.1$ & $35.1 \pm 1.2$ \\
\hline \multicolumn{5}{|l|}{$\mathrm{SaO}_{2}(\%)$} \\
\hline \multicolumn{5}{|l|}{ HLNB } \\
\hline $\mathrm{NaCl} 0.9 \%$ & $67.4 \pm 2.9^{*}$ & $64.5 \pm 3.2 *$ & $50.3 \pm 2.9 \dagger$ & $66.6 \pm 3.5^{*}$ \\
\hline Sildenafil & $74.6 \pm 2.4 \ddagger$ & $71.9 \pm 3.6$ & $47.8 \pm 3.0 \dagger$ & $72.6 \pm 3.2$ \\
\hline \multicolumn{5}{|l|}{ LLNB } \\
\hline $\mathrm{NaCl} 0.9 \%$ & $94.7 \pm 0.7$ & $93.5 \pm 1.2$ & $52.7 \pm 3.1 \dagger$ & $96.0 \pm 0.7$ \\
\hline Sildenafil & $95.8 \pm 0.8$ & $94.8 \pm 1.0$ & $54.1 \pm 2.3 \dagger$ & $95.9 \pm 0.6$ \\
\hline \multicolumn{5}{|l|}{$\mathrm{Hb}\left(\mathrm{g} \cdot \mathrm{dL}^{-1}\right)$} \\
\hline \multicolumn{5}{|l|}{ HLNB } \\
\hline $\mathrm{NaCl} 0.9 \%$ & $11.4 \pm 0.8$ & $12.1 \pm 0.7$ & $12.4 \pm 0.8$ & $11.8 \pm 0.8$ \\
\hline Sildenafil & $13.0 \pm 0.9^{*}$ & $12.6 \pm 0.9$ & $12.9 \pm 0.9$ & $12.5 \pm 0.9$ \\
\hline \multicolumn{5}{|l|}{ LLNB } \\
\hline $\mathrm{NaCl} 0.9 \%$ & $10.9 \pm 0.5^{*}$ & $11.0 \pm 0.5$ & $11.3 \pm 0.4$ & $10.3 \pm 0.4$ \\
\hline Sildenafil & $9.8 \pm 0.5$ & $10.1 \pm 0.5$ & $10.2 \pm 0.4$ & $9.6 \pm 0.3$ \\
\hline \multicolumn{5}{|c|}{$\mathrm{O}_{2}$ cont $\left(\mathrm{mL} \mathrm{O}_{2} \cdot \mathrm{dL}^{-1}\right)$} \\
\hline \multicolumn{5}{|c|}{ HLNB } \\
\hline $\mathrm{NaCl} 0.9 \%$ & $10.6 \pm 0.8^{*}$ & $10.9 \pm 0.9^{*}$ & $8.7 \pm 0.8 \dagger$ & $10.9 \pm 1.0^{*}$ \\
\hline Sildenafil & $13.1 \pm 0.9$ & $12.2 \pm 0.8$ & $8.4 \pm 0.7 \dagger$ & $12.1 \pm 0.6$ \\
\hline \multicolumn{5}{|l|}{ LLNB } \\
\hline $\mathrm{NaCl} 0.9 \%$ & $13.9 \pm 0.6$ & $13.9 \pm 0.6$ & $8.0 \pm 0.5 \dagger$ & $13.3 \pm 0.6$ \\
\hline Sildenafil & $12.8 \pm 0.5$ & $13.1 \pm 0.6$ & $7.4 \pm 0.4 \dagger$ & $12.7 \pm 0.4$ \\
\hline
\end{tabular}

Values are given as mean \pm SEM in basal, basal plus infusion (Basal + I), hypoxia plus infusion (Hypoxia + I), and recovery. pHa, Significant differences $p<0.05: \dagger v s$ basal; $\ddagger v s \mathrm{NaCl} 0.9 \%$ (control); * vs LLNB with the same treatment.

LLNB. As in the HLNB, the LLNB (control group) had a brisk increase in PAP during acute hypoxia, which was maintained until the end of the episode (Fig. 1), associated with an increase in CO, PVR, and HR (Figs. 1 and 2, Table 2). All these variables returned to basal values in the recovery period (Figs. 1 and 2, Table 2). With the sildenafil infusion, there was an initial decrease in PAP and SAP with an increase in HR (Fig. 1, Table 2). During the hypoxic episode, PAP returned to basal values, but PVR remained low with the hypoxia onset (Figs. 1 and 2). In contrast, the SAP recovered the initial basal values during hypoxia (Table 2); nevertheless, SVR remained low and HR and CO increased as in the control group during hypoxia (Table 2 ).

Response to $\mathbf{K C l}$. The HLNB had a maximum response to $\mathrm{K}^{+}$of $1.93 \pm 0.09 \mathrm{~N} \mathrm{~m}^{-1}$, which was higher than LLNB $\left(1.16 \pm 0.05 \mathrm{~N} \mathrm{~m}^{-1}, p<0.05\right)$. However, both groups showed a similar potency $\left(\mathrm{EC}_{50}=26.71 \pm 1.95 \mathrm{mM} \mathrm{HLNB}\right.$ and $31.53 \pm 4.43 \mathrm{mM} \mathrm{LLNB}$ ) to $\mathrm{KCl}$ (Fig. 3).

Response to sildenafil. Increasing doses of sildenafil induced a concentration-dependent relaxation in pulmonary arteries precontracted with $50 \mathrm{mM} \mathrm{KCl}$ from both groups. The maximum response to sildenafil was higher in HLNB (62.5 \pm $1.6 \% \mathrm{Kmax})$ than LLNB $(46.3 \pm 2.7 \% \mathrm{Kmax}, p<0.05)$, without differences in $\mathrm{pD}_{2}(10.6 \pm 0.1$ HLNB and $10.2 \pm 0.2$ LLNB) (Fig. 4).

Response to SNP. The NO-donor SNP evoked a relaxation in HLNB of $71.8 \pm 1.9 \% \mathrm{Kmax}$ that was higher in LLNB $(100 \pm 2.4 \% \mathrm{Kmax}, p<0.05)$. However, HLNB showed a higher $\mathrm{pD}_{2}(6.34 \pm 0.09)$ than LLNB $(5.77 \pm 0.07, p<0.05)$ (Fig. 5). The NO-induced relaxation was completely abolished in both groups when $\mathrm{SGC}$ was blocked with ODQ $\left(10^{-5} \mathrm{M}\right)$ plus SNP from $10^{-10}$ to $10^{-3} \mathrm{M}$ (not shown). 

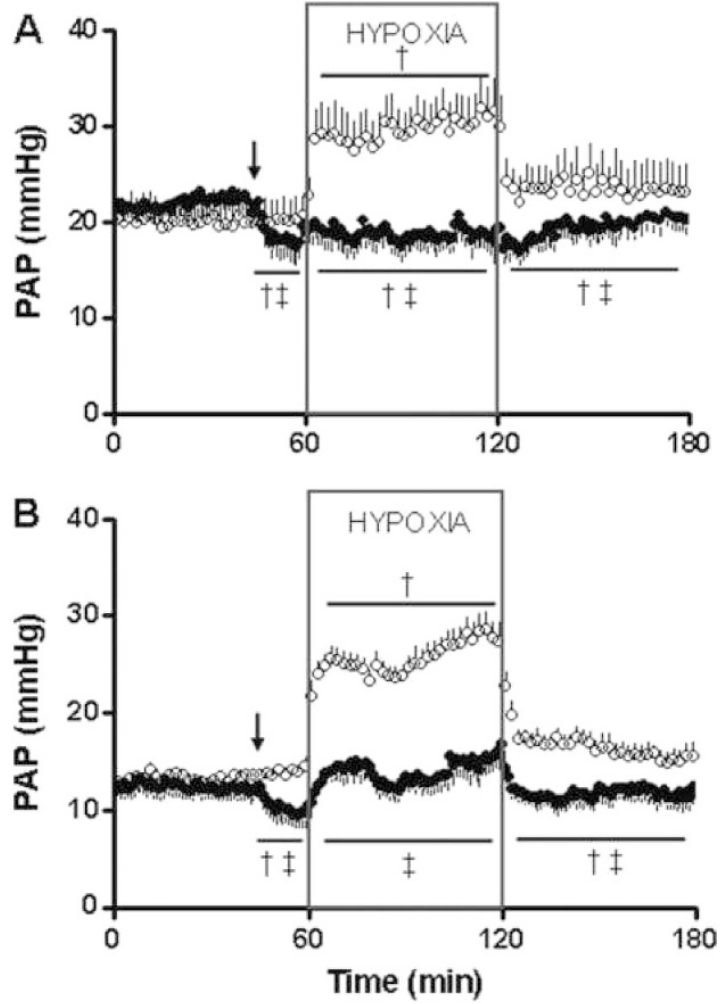

Figure 1. PAP in HLNB $(A)$ and LLNB $(B)$. Continuous measurement of PAP during the 180-min protocol with $\mathrm{NaCl} 0.9 \%$ (control, $\bigcirc$ ) or sildenafil infusion (-). Arrow shows the start of the infusion $15 \mathrm{~min}$ before the onset of hypoxia. Values expressed as mean \pm SEM. Significant differences $p<0.05$ : $\dagger v s$ basal; $\ddagger v s \mathrm{NaCl} 0.9 \%$ (control).
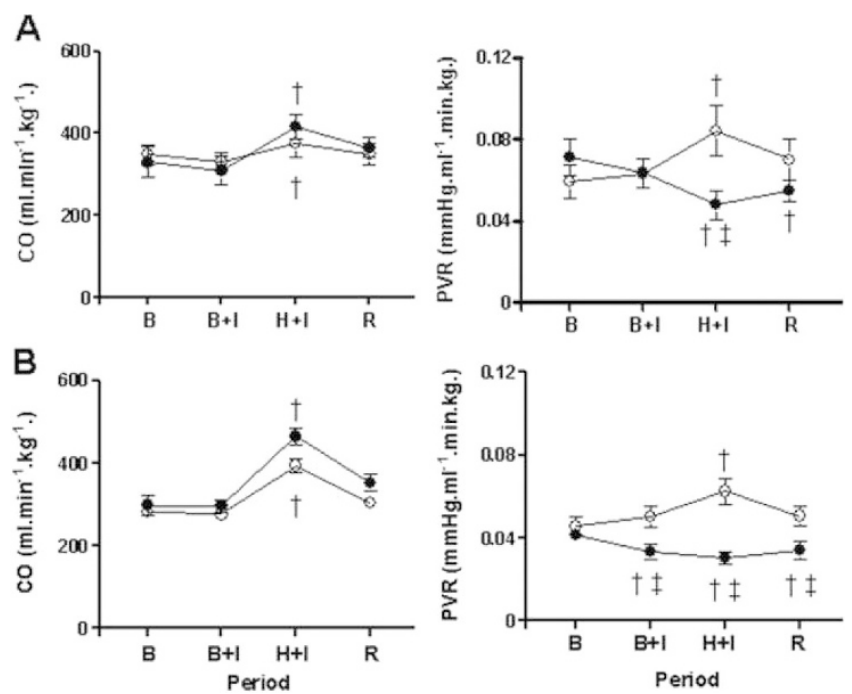

Figure 2. CO and PVR in HLNB $(A)$ and LLNB $(B)$ newborn sheep. Means of the different experimental periods: basal $(B)$, basal plus infusion $(B+I)$, hypoxia plus infusion $(\mathrm{H}+\mathrm{I}$ ), and recovery $(\mathrm{R})$ with $\mathrm{NaCl} 0.9 \%$ (control, $\bigcirc$ or sildenafil infusion $(-)$. Bar shows the periods where the infusion was administered $(\mathrm{B}+\mathrm{I}$ and $\mathrm{H}+\mathrm{I})$. Values expressed as means $\pm \mathrm{SEM}$. Significant differences $p<0.05$ : $\dagger v$ sbasal; $\ddagger v s \mathrm{NaCl} 0.9 \%$ (control).

PDE5 mRNA expression. The RT-PCR analyses showed no significant differences between the mRNA expression of PDE5 in lung tissue between HLNB and LLNB (0.983 \pm 0.099 versus $0.798 \pm 0.116$ relative units PDE5/18S).
Small pulmonary artery histology. Morphometric analysis of the pulmonary distal vasculature revealed a significant difference in vessel wall thickness between HLNB and LLNB (62 $\pm 4 \%$ versus $48 \pm 5 \%$, respectively, $p<0.05$, Fig. 6).

\section{DISCUSSION}

In this work, we have shown that sildenafil played a role in regulating the basal PAP at high and low altitudes. In addition, there was an outstanding blunting of the substantial increase in PAP during hypoxia in high and low altitude lambs. Even more, the PAP in the HLNB during hypoxia plus sildenafil was lower than the basal PAP, despite the increase in $\mathrm{CO}$ during hypoxia, indicating a significant pulmonary vasodilatation. These results suggest that the increase in PAP observed in acute hypoxia in highland and lowland lambs could be mediated in part by the absence of cGMP vasodilator effect due to destruction of the cGMP by PDE5. With sildenafil, the cGMP action is restored, particularly in the HLNB, because sildenafil not only blunted the increase in PAP, but also reduced PAP and PVR in pulmonary hypertensive lambs. In addition, it was confirmed that the NO-induced vasodilatation in these small pulmonary arteries is exclusively mediated by cGMP and that the blockade of PDE5 produces greater vasodilatation in chronically hypoxic newborns than in normoxic lambs. Combined, this in vivo and ex vivo outcome indicated that hypoxia stimulated considerably PDE5 function. Furthermore, the HLNB showed remodeling in distal small pulmonary arteries, with thickened media associated to the pulmonary hypertension.

The decrease in SAP was of lesser degree and duration compared with pulmonary pressure. The greater vasodilatation with sildenafil observed in the myographic studies in the HLNB suggests that chronic hypoxia induces a higher function of PDE5, a phenomenon supported by previous reports $(15-17)$. Although there was a tendency to increase PDE5 mRNA in HLNB, we did not find significant differences between the HLNB and LLNB. Therefore, the different myographic responses to sildenafil may be explained by a higher PDE5 protein expression and/or activity in our pulmonary hypertensive lambs $(15,16)$. However, we did not determine the protein expression or activity of the enzyme to ascertain this mechanism. PDE5 activity is enhanced by phosphorylation through cGMP availability and PKG enzymatic activity (11), resulting in lower cGMP levels. This, in turn, may favor the enhanced contractile status seen in the HLNB (1). Sildenafil is a potent vasodilator in pulmonary arteries of chronically hypoxic rats, normalizing the $\left[\mathrm{Ca}^{2+}\right]_{\mathrm{i}}$ levels (18) and increasing cGMP availability (19). In addition, sildenafil also acts in endothelial NO synthase (eNOS)-deficient mice, generating substantial pulmonary vasodilatation even when eNOS activity is impaired (20).

The partial reversal in pulmonary hypertension observed in HLNB during the basal period is due to blunting of vasoconstriction. In addition, the remodeling observed in these animals may explain the absence of total reversion of the elevated PAP. Consistent with our observations in vivo 
Table 2. Cardiorespiratory variables in HLNB and LLNB during the experimental protocol of NaCl $0.9 \%$ (control) or sildenafil infusion

\begin{tabular}{|c|c|c|c|c|}
\hline & Basal & Basal + I & Hypoxia + I & Recovery \\
\hline \multicolumn{5}{|c|}{ Mean SAP (mm Hg) } \\
\hline \multicolumn{5}{|c|}{ HLNB } \\
\hline $\mathrm{NaCl} 0.9 \%$ & $80 \pm 3$ & $79 \pm 3$ & $82 \pm 3$ & $79 \pm 3$ \\
\hline \multicolumn{5}{|l|}{ LLNB } \\
\hline $\mathrm{NaCl} 0.9 \%$ & $81 \pm 1$ & $82 \pm 1$ & $81 \pm 2$ & $82 \pm 1$ \\
\hline Sildenafil & $81 \pm 2$ & $73 \pm 5 \dagger t$ & $76 \pm 2$ & $77 \pm 3$ \\
\hline $\mathrm{NaCl} 0.9 \%$ & $0.234 \pm 0.015$ & $0.243 \pm 0.014$ & $0.228 \pm 0.019$ & $0.230 \pm 0.015$ \\
\hline Sildenafil & $0.265 \pm 0.032$ & $0.253 \pm 0.037$ & $0.187 \pm 0.015 \dagger$ & $0.212 \pm 0.015$ \\
\hline \multicolumn{5}{|l|}{ LLNB } \\
\hline $\mathrm{NaCl} 0.9 \%$ & $0.297 \pm 0.013$ & $0.307 \pm 0.016$ & $0.209 \pm 0.008 \dagger$ & $0.275 \pm 0.010$ \\
\hline Sildenafil & $0.278 \pm 0.016$ & $0.247 \pm 0.010 \ddagger$ & $0.165 \pm 0.006 \dagger$ & $0.223 \pm 0.015$ \\
\hline \multicolumn{5}{|l|}{$\operatorname{HR}\left(\min ^{-1}\right)$} \\
\hline $\mathrm{NaCl} 0.9 \%$ & $198 \pm 8$ & $193 \pm 8$ & $268 \pm 12 \dagger$ & $208 \pm 7$ \\
\hline Sildenafil & $163 \pm 12$ & $221 \pm 14 \dagger$ & $294 \pm 7 \dagger$ & $215 \pm 14$ \\
\hline \multicolumn{5}{|c|}{ Stroke volume $\left(\mathrm{mL} \cdot \mathrm{kg}^{-1}\right)$} \\
\hline \multicolumn{5}{|c|}{ HLNB } \\
\hline $\mathrm{NaCl} 0.9 \%$ & $1.68 \pm 0.15$ & $1.62 \pm 0.18$ & $1.45 \pm 0.13$ & $1.77 \pm 0.26$ \\
\hline Sildenafil & $1.74 \pm 0.18$ & $1.42 \pm 0.15$ & $1.52 \pm 0.07$ & $1.64 \pm 0.18$ \\
\hline \multicolumn{5}{|l|}{ LLNB } \\
\hline $\mathrm{NaCl} 0.9 \%$ & $1.39 \pm 0.07$ & $1.40 \pm 0.07$ & $1.49 \pm 0.11$ & $1.44 \pm 0.05$ \\
\hline Sildenafil & $1.84 \pm 0.07$ & $1.36 \pm 0.08 \dagger$ & $1.59 \pm 0.09$ & $1.68 \pm 0.12$ \\
\hline
\end{tabular}

Values are given as mean \pm SEM in basal, basal plus infusion (Basal $+\mathrm{I})$, hypoxia plus infusion (Hypoxia + I), and recovery. Significant differences $p<$ 0.05 : $\dagger v s$ basal; $\ddagger v s \mathrm{NaCl} 0.9 \%$ (control); *vs LLNB with the same treatment.
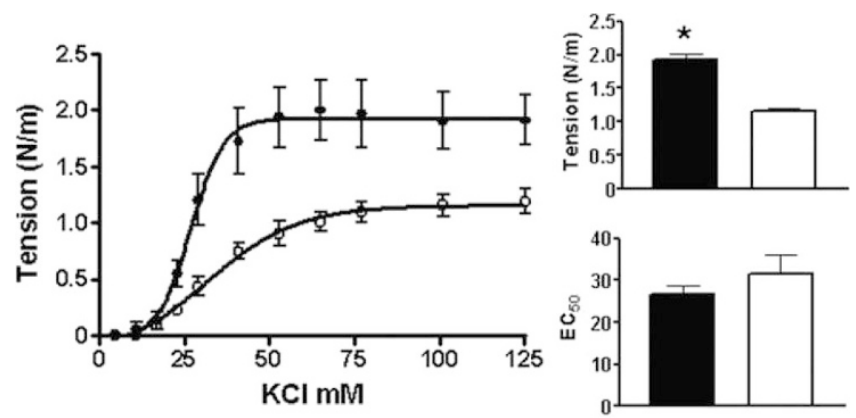

Figure 3. Responses to $\mathrm{KCl}$ in pulmonary small arteries from HLNB $(\bullet$ and solid columns) and LLNB ( $\bigcirc$ and open columns). Values are shown as mean \pm SEM. Significant differences $p<0.05: * v s$ LLNB.
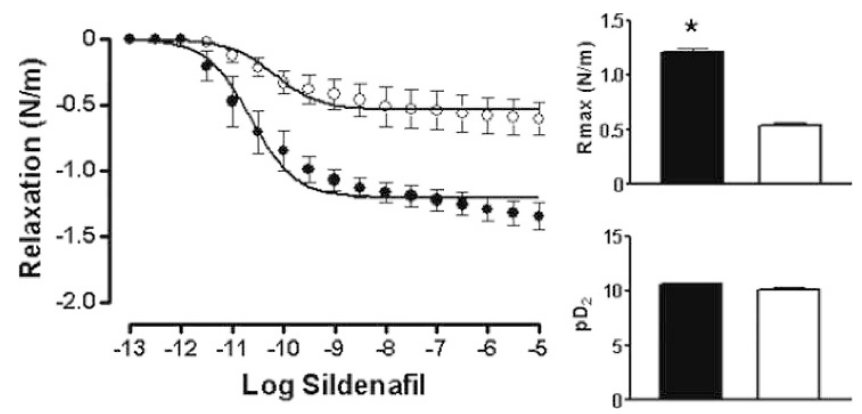

Figure 4. Responses to sildenafil in pulmonary small arteries from HLNB ( and solid columns) and LLNB ( $\bigcirc$ and open columns). Values are shown as means \pm SEM. Significant differences $p<0.05: * v s$ LLNB.
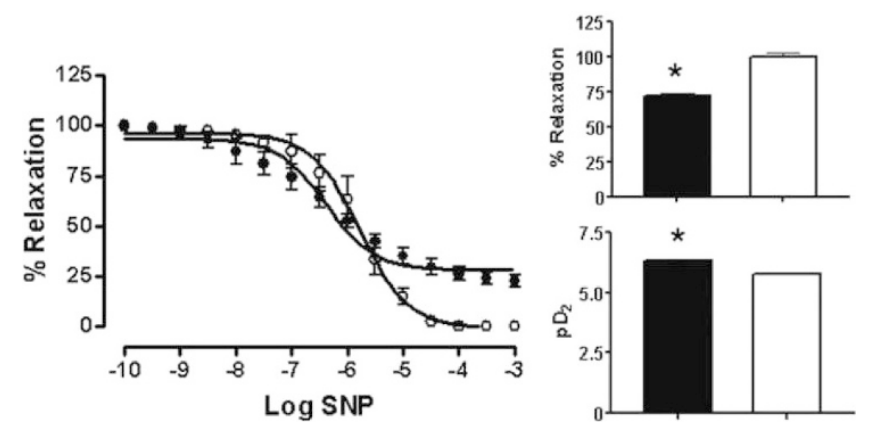

Figure 5. Responses to SNP in pulmonary small arteries from HLNB ( and solid columns) and LLNB ( $\bigcirc$ and open columns) newborn sheep. Values are shown as mean \pm SEM. Significant differences $p<0.05: * v s$ LLNB.

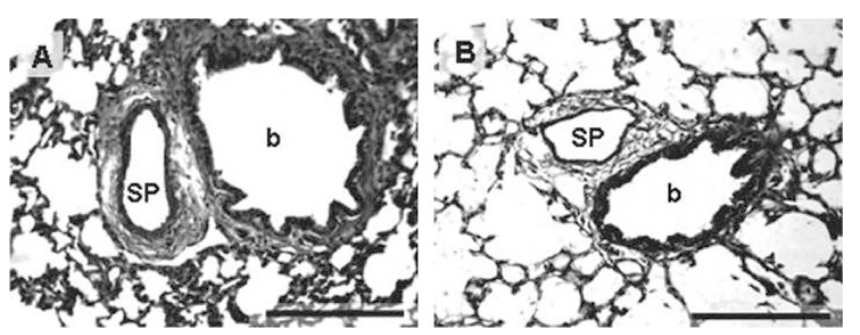

Figure 6. Representative micrograph of subpleural pulmonary small arteries from HLNB $(A)$ and LLNB $(B)$. van Gieson staining. SP, subpleural artery; b, bronchiole. Bar: $100 \mu \mathrm{m}$.

and ex vivo, there was a remodeling in the subpleural arterioles, which is an effect of perinatal chronic hypoxia. The present study is unable to determine the age at which 
these histologic changes occurred, but it nevertheless is representative of high-altitude populations. However, it is known that the magnitude of the chronic hypoxia-induced changes depends on the species, the age, and the intensity of hypoxia (21).

Exposure to chronic hypoxia results in high pulmonary pressure associated with a histologic fetal pattern of thickened media (22) as seen in our newborns. This thickening of the media is due to a muscle hypertrophy and deposition of matrix proteins, such as collagen and elastin $(21,23,24)$. Hypoxic calves with pulmonary hypertension showed similar patterns of remodeling as our HLNB at $15 \mathrm{~d}$ old (23). The mechanisms that produce these responses are yet not fully understood (21). Currently, neonatal pulmonary hypertension has a variety of treatments depending on the intensity of hypertension and hypoxia (25-31), and the mortality rate is still high $(28,32)$. In this scenario, sildenafil is a novel, inexpensive, easy-to-obtain and administer drug and preliminary trials show its potential use in decreasing PAP (12,26,32-35). The reported doses in newborns $(26,36,37)$ are similar to our dose of $1.2 \mathrm{mg} \cdot \mathrm{kg}^{-1}$ in a 75-min infusion. The slow administration may be beneficial with no or few unwanted effects in the systemic vascular bed. Some authors have established combinations as sildenafil-inhaled NO (38), sildenafil surfactant (35), or sildenafil bosentan (30), with effective pulmonary results. Although sildenafil is a very good drug for pulmonary hypertension treatment, it is necessary to evaluate the side effects such as systemic hypotension, gastric alterations (39), retinal vascular damage $(40,41)$, neurologic, and psychological disturbances $(42,43)$.

In this study, we have shown that pulmonary NO vasodilatation occurs exclusively via sGC-cGMP and the PDE5 function may be increased in HLNB. Finally, sildenafil is effective in decreasing PAP, even in the presence of pulmonary vascular remodeling and precluding a dangerous increase in pulmonary pressure in episodes of acute hypoxia. The mechanisms responsible for the sildenafil effect under high altitude conditions will require further studies.

Acknowledgments. The authors thank Carlos Brito, Gabino Llusco, and Enrique Pérez for technical assistance. Sildenafil was kindly donated by Laboratorio Chile S.A. Emilio Herrera is a fellow of Programa MECESUP UCh0115 and Beca Universidad de Chile PG/54/2005.

\section{REFERENCES}

1. Herrera EA, Pulgar VM, Riquelme RA, Sanhueza EM, Reyes RV, Ebensperger G, Parer JT, Valdez EA, Giussani DA, Blanco CE, Hanson MA, Llanos AJ 2007 High-altitude chronic hypoxia during gestation and after birth modifies cardiovascular responses in newborn sheep. Am J Physiol Regul Integr Comp Physiol 292:R2234-R2240

2. Tucker A, McMurtry IF Reeves JT, Alexander AF, Will DH, Grover RF 1975 Lung vascular smooth muscle as a determinant of pulmonary hypertension at altitude. Am J Physiol 228:762-767

3. Monge C, Leon-Velarde F 1991 Physiological adaptation to high altitude: oxygen transport in mammals and birds. Physiol Rev 71:1135-1172

4. Jeffery TK, Morrell NW 2002 Molecular and cellular basis of pulmonary vascular remodeling in pulmonary hypertension. Prog Cardiovasc Dis 45:173-202

5. Abman SH 1999 Abnormal vasoreactivity in the pathophysiology of persistent pulmonary hypertension of the newborn. Pediatr Rev 20:e103-e109
6. Walsh-Sukys MC, Tyson JE, Wright LL, Bauer CR, Korones SB, Stevenson DK, Verter J, Stoll BJ, Lemons JA, Papile LA, Shankaran S, Donovan EF, Oh W, Ehrenkranz RA, Fanaroff AA 2000 Persistent pulmonary hypertension of the newborn in the era before nitric oxide: practice variation and outcomes. Pediatrics 105:14-20

7. Keyes LE, Armaza JF, Niermeyer S, Vargas E, Young DA, Moore LG 2003 Intrauterine growth restriction, preeclampsia, and intrauterine mortality at high altitude in Bolivia. Pediatr Res 54:20-25

8. Peñaloza D, Arias-Stella $\mathrm{J} 2007$ The heart and pulmonary circulation at high altitudes: healthy highlanders and chronic mountain sickness. Circulation 115:1132-1146

9. Shimoda LA, Sham JS, Sylvester JT 2000 Altered pulmonary vasoreactivity in the chronically hypoxic lung. Physiol Res 49:549-560

10. Le Cras TD, McMurtry IF 2001 Nitric oxide production in the hypoxic lung. Am J Physiol Lung Cell Mol Physiol 280:L575-L582

11. Rybalkin SD, Yan C, Bornfeldt KE, Beavo JA 2003 Cyclic GMP phosphodiesterases and regulation of smooth muscle function. Circ Res 93:280-291

12. Weimann J, Ullrich R, Hromi J, Fujino Y, Clark MW, Bloch KD, Zapol WM 2000 Sildenafil is a pulmonary vasodilator in awake lambs with acute pulmonary hypertension. Anesthesiology 92:1702-1712

13. Shekerdemian LS, Ravn HB, Penny DJ 2002 Intravenous sildenafil lowers pulmonary vascular resistance in a model of neonatal pulmonary hypertension. Am J Respir Crit Care Med 165:1098-1102

14. Minamino T, Christou H, Hsieh CM, Liu Y, Dhawan V, Abraham NG, Perrella MA, Mitsialis SA, Kourembanas S 2001 Targeted expression of heme oxygenase-1 prevents the pulmonary inflammatory and vascular responses to hypoxia. Proc Nat Acad Sci U S A 98:8798-8803

15. Maclean MR, Johnston ED, Mcculloch KM, Pooley L, Houslay MD, Sweeney G 1997 Phosphodiesterase isoforms in the pulmonary arterial circulation of the rat: changes in pulmonary hypertension. J Pharmacol Exp Ther 283:619-624

16. Hanson KA, Ziegler JW, Rybalkin SD, Miller JW, Abman SH, Clarke WR 1998 Chronic pulmonary hypertension increases fetal lung cGMP phosphodiesterase activity. Am J Physiol 275:L931-L941

17. Murray F, MacLean MR, Pyne NJ 2002 Increased expression on the cGMP-inhibited cAMP-specific (PDE3) and cGMP binding cGMP-specific (PDE5) phosphodiesterases in models of pulmonary hypertension. Br J Pharmacol 137:1187-1194

18. Pauvert O, Bonnet S, Rousseau E, Marthan R, Savineau JP 2004 Sildenafil alters calcium signaling and vascular tone in pulmonary arteries from chronically hypoxic rats. Am J Physiol Lung Cell Mol Physiol 287:L577-L583

19. Mauricio MD, Segarra G, Medina P, Aldasoro M, Martinez-Leon JB, Vila JM 2006 Relaxation and cyclic GMP levels in response to sildenafil in human pulmonary arteries from donors. Eur J Pharmacol 530:259-262

20. Zhao L, Mason NA, Morrell NW, Kojonazarov B, Sadykov A, Maripov A, Mirrakhimov MM, Aldashev A, Wilkins MR 2001 Sildenafil inhibits hypoxiainduced pulmonary hypertension. Circulation 104:424-428

21. Stenmark KR, Fagan KA, Frid MG 2006 Hypoxia-induced pulmonary vascular remodeling: cellular and molecular mechanisms. Circ Res 99:675-691

22. Maggiorini M 2003 Cardio-pulmonary interactions at high altitude. Pulmonary hypertension as a common denominator. Adv Exp Med Biol 543:177-189

23. Durmowicz AG, Stenmark KR 1999 Mechanisms of structural remodelling in chronic pulmonary hypertension. Pediatr Rev 20:e91-e102

24. Stenmark KR, Davie N, Frid M, Gerasimovskaya E, Das M 2006 Role of the adventitia in pulmonary vascular remodeling. Physiology (Bethesda) 21:134 145

25. Kinsella JP, Abman SH 2000 Clinical approach to inhaled nitric oxide therapy in the newborn with hypoxemia. J Pediatr 136:717-726

26. Baquero H, Soliz A, Neira F, Venegas ME, Sola A 2006 Oral sildenafil in infants with persistent pulmonary hypertension of the newborn: a pilot randomized blinded study. Pediatrics 117:1077-1083

27. Lorch SA, Cnaan A, Barnhart K 2004 Cost-effectiveness of inhaled nitric oxide for the management of persistent pulmonary hypertension of the newborn. Pediatrics 114:417-426

28. Walsh MC, Stork EK 2001 Persistent pulmonary hypertension of the newborn. Clin Perinatol 28:609-627

29. Keogh AM, McNeil KD, Williams T, Gabbay E, Cleland LG 2003 Pulmonary arterial hypertension: a new era in management. Med J Aust 178:564-567

30. Mathai SC, Girgis RE, Fisher MR, Champion HC, Housten-Harris T, Zaiman A, Hassoun PM 2007 Addition of sildenafil to bosentan monotherapy in pulmonary arterial hypertension. Eur Respir J 29:469-475

31. Shekerdemian LS, Penny DJ, Ryhammer PK, Reader JA, Ravn HB 2004 Endothelin-A receptor blockade and inhaled nitric oxide in a porcine model of meconium aspiration syndrome. Pediatr Res 56:353-358

32. Travadi JN, Patole SK 2003 Phosphodiesterase inhibitors for persistent pulmonary hypertension of the newborn: a review. Pediatr Pulmonol 36:529-535

33. Ichinose F, Erana-Garcia J, Hromi J, Raveh Y, Jones R, Krim L, Clark MW, Winkler JD, Bloch KD, Zapol WM 2001 Nebulized sildenafil is a selective pulmonary vasodilator in lambs with acute pulmonary hypertension. Crit Care Med 29:10001005

34. Carroll WD, Dhillon R 2003 Sildenafil as a treatment for pulmonary hypertension. Arch Dis Child 88:827-828

35. Obaid L, Johnson ST, Bigam DL, Cheung PY 2006 Intratracheal administration of sildenafil and surfactant alleviates the pulmonary hypertension in newborn piglets. Resuscitation 69:287-294 
36. Binns-Loveman KM, Kaplowitz MR, Fike CD 2005 Sildenafil and an early stage of chronic hypoxia-induced pulmonary hypertension in newborn piglets. Pediatr Pulmonol 40:72-80

37. Juliana AE, Abbad FC 2005 Severe persistent pulmonary hypertension of the newborn in a setting where limited resources exclude the use of inhaled nitric oxide: successful treatment with sildenafil. Eur J Pediatr 164:626-629

38. Shekerdemian LS, Ravn HB, Penny DJ 2004 Interaction between inhaled nitric oxide and intravenous sildenafil in a porcine model of meconium aspiration syndrome. Pediatr Res 55:413-418

39. de Rosalmeida MC, Saraiva LD, da Graca JR, Ivo BB, da Nobrega MV, Gondim FA, Rola FH, dos Santos AA 2003 Sildenafil, a phosphodiesterase-5 inhibitor, delays gastric emptying and gastrointestinal transit of liquid in awake rats. Dig Dis Sci 48:2064-2068
40. Balacco Gabrieli C, Regine F, Vingolo EM, Rispoli E, Isidori A 2003 Acute electroretinographic changes during sildenafil (Viagra) treatment for erectile dysfunction. Doc Ophthalmol 107:111-114

41. Marsh CS, Marden B, Newsom R 2004 Severe retinopathy of prematurity (ROP) in a premature baby treated with sildenafil acetate (Viagra) for pulmonary hypertension. Br J Ophthalmol 88:306-307

42. Milman HA, Arnold SB 2002 Neurologic, psychological, and aggressive disturbances with sildenafil. Ann Pharmacother 36:1129-1134

43. Wang M, Urenjak J, Fedele E, Obrenovitch TP 2004 Effects of phosphodiesterase inhibition on cortical spreading depression and associated changes in extracellular cyclic GMP. Biochem Pharmacol 67:1619-1627 